\title{
O fantástico e os discursos do saber ${ }^{1}$
}

\author{
Patricia Willemin ${ }^{2}$
}

RÉSUMÉ: Le présent article aborde les rapports entre les textes fantastiques traditionnels et le savoir scientifique. L'analyse de récits fantastiques canoniques écrits à partir du XVIII siècle - tels que Le Moine de Lewis, Frankenstein de Mary Shelley et Dracula de Bram Stoker - montre que le surnaturel finit toujours par supplanter le savoir. De fait, même si les théories scientifiques évoluent et que les hommes s'y rattachent, il existe des événements qui ne sont pas explicables par la raison et qui entraînent le désordre du pouvoir cognitif.

MOTS-CLÉS: fantastique, surnaturel, savoir scientifique, raison

Pode parecer curioso ligar o fantástico ao cognitivo. Como em toda prática discursiva proveniente da oralidade, a única forma de saber convocada por esse gênero é um saber narrativo, com enunciados prescritivos e avaliativos (Lyotard). Mas só se trata disso? Não poderíamos pensar que a concepção do fantástico permanece estreitamente ligada à elaboração de uma teoria do conhecimento? ${ }^{2}$ Saber e falso-saber, racionalismo e magia: noções irreconciliáveis e, entretanto, coexistentes no discurso fantástico, desde sua emergência, no fim do século XVIII. Experimentando completamente os saberes científicos (eletricidade, magnetismo, geometria nãoeuclidiana), determinados textos apresentam-se como uma reflexão sobre a ciência ou, decididamente, uma crítica do poder cognitivo. Não expressariam, então, a impossibilidade do conhecimento extensivo? No decurso da análise de algumas produções, principalmente anglo-saxônicas (Matthew G. Lewis, Mary Shelley, Edgar Allan Poe, Bram Stoker, Henry James e H. P.

Patricia Willemin é professora no Collège Français de Montreal.

${ }^{1}$ Este texto foi publicado pela primeira vez sob o titulo "Le fantastique et les discours du savoir "em língua francesa na Revue Langage et Savoir, Montréal, printemps 1985, vol. 13, n 1: 107-111. (Protée, primavera de 1985, p. 107-111)

${ }^{2} \mathrm{~J} . \mathrm{L}$. Borges, Manuel de zoologie fantastique, Julliard, 1970. 
Lovecraft), trataremos de questionar as relações mantidas por esse gênero com o saber. ${ }^{3}$

Esclarecemos que a análise somente tratará a respeito de textos relevantes do fantástico tradicional ou canônico, que definimos como segue: em um mundo real, tranqüilizador, surge repentinamente um caso, um acontecimento desafiando as leis da razão. Esse tipo de discurso pressupõe a noção de dualismo; dois universos radicalmente opostos coexistem: o real (o humano) e o supra-real (o inumano). $\mathrm{O}$ acontecimento em questão estigmatiza o início da relação desses dois sistemas. Por outro lado, o fantástico canônico aposta sempre no medo, descrevendo as reações dos sujeitos que se defrontam com o sobrenatural (Diabo, entidades) e suas mediações (fantasmas, vampiros, etc.). Vemos que não se trata de limitar-se às posições de Todorov sobre o tema e de excluir, para os fins da análise, as obras que não respondem aos critérios sutis da hesitação ou da ambigüidade.

De origem popular (literatura folhetinesca), o fantástico surgiu no final do século XVIII, no momento em que os contos de fadas já estavam bem estabelecidos. Dessas narrativas curtas, o gênero tomará emprestado o quadro sobrenatural, mas também (e sobretudo) a relação constante com os valores morais e o princípio do retorno à ordem. Um tipo de saber aí se desenha: o saber não-científico, ou saber-narrativo. Lyotard caracteriza-o como "um conjunto de enunciados denotativos, mas também de saberfazer, saber-viver (...) (que) conferem capacidade de proferir bons enunciados prescritivos e avaliativos" ${ }^{5}$ Essa forma cognitiva visa, antes de tudo, fundar uma comunidade de espírito e determina aquele que tem o direito de se desenvolver em uma cultura.

\section{O monge de Lewis ou o saber prescritivo}

Um dos primeiros textos fantásticos, $O$ monge, de Lewis, publicado em 1795, apresenta enunciados preliminares apoiados em uma estrutura da comunicação narrador/narratário. Como o contador, o narrador toma o encargo de uma diegese que lhe permite separar o Falso do Verdadeiro. Trata-se de derrubar as máscaras, de revelar a hipocrisia da sociedade espanhola:

${ }^{3}$ Cf. M. Foucault, L'archéologie du savoir, Gallimard, 1969, p. 239.

${ }^{4} \mathrm{~T}$. Todorov, Introduction à la littérature fantastique, Seuil, 1970, p. 35.

${ }^{5}$ J. F. Lyotard, La condition postmoderne, Minuit, 1979, p. 37. 
Não vá acreditar que esta afluência teve por causa a devoção ou a sede de se instruir. (...) O público

reunido na igreja dos Capuchinhos aí estava atraído por razões diversas, mas todas alheias ao motivo ostensivo. ${ }^{6}$

Do mesmo modo, o fechamento do romance repousa numa estratégia de escritura de viés moralizante:

Senhora, ser indulgente com a conduta do próximo não é uma virtude menor que ser rigoroso com a sua.

Como na tradição oral, o fantástico propõe bildungen (aprendizagens ou formações). Formações extradiegéticas, mas também intradiegéticas. Dois longos capítulos (o III e o IV) são reservados a um narrador homodiegético, Don Raymond de las Cisternas, que por intermédio de suas viagens ao estrangeiro faz o relato de sua formação e da aquisição de seu saber. Na Alemanha, Don Raymond conhece o sobrenatural: a famosa freira ensangüentada. Esse fantasma, no qual todo o mundo acredita, assombra o castelo de Lindenberg a cada cinco anos, no dia 5 de maio, à meianoite. $\mathrm{O}$ incrédulo Raymond, após algumas noites de pesadelos e o exorcismo realizado pelo Judeu errante, deverá reconhecer os valores da tradição cultural: os fantasmas realmente existem.

Mas, por intermédio desse enredo bastante clássico, o Monge responsabiliza sobretudo a educação perniciosa dos conventos latinos, que faz do sujeito Ambrósio objeto de predileção do Mal. Por uma educação às avessas, o monge torna-se uma figura da desordem (estupro, incesto, parricídio). É interessante notar que é a mulher-demônio Mathilde que desempenha o papel de pedagoga. Detém o saber oculto que permite a plenitude dos desejos. Conhece a linguagem secreta, as fórmulas invertidas. Por ela, a escrita e os sons se atualizam. Por ela, Ambrósio alcançará o saber individual, com o conhecimento de si e do mundo. Assim Mathilde abre o caminho (a personagem de Biondetta em $O$ diabo enamorado, de Cazotte, precedeu-a um pouco) para esta longa linhagem de mulheres-demônios/mulheres cultas da literatura. Entretanto, se a sedutora termina impune, gloriosa, o transgressor Ambrósio somente pode ser punido. Ele o será, por uma justiça transcendente (paradoxalmente, Lúcifer), pois o braço religioso-secular (a Inquisição) não está conotado positivamente no romance. Como nos contos populares, o respeito às convenções morais impõe-se: os

${ }^{6}$ M. Lewis, Le Moine, Marabout, 1967, p. 11. 
desregramentos individuais e sociais (a cena do linchamento da abadessa pelo povo) não poderiam ser admitidos na sociedade inglesa pré-industrial. Em filigrana inscreve-se, bem entendido, a condenação da desordem revolucionária e do Terror francês?

Desde sua origem, o fantástico afirma, portanto, o retorno à ordem, à ética. Toda a produção do romance negro, de 1764 a 1818, apresenta como esquema narrativo básico a transgressão punida e o triunfo da moral. Essa invariante marca igualmente o gênero de Stevenson a Thomas Owen. Neste último, os enunciados prescritivos situam-se quase sempre no paratexto. As epígrafes são do tipo: "Não passeis de uma vida a outra" ou "Não é preciso destruir um sonho" ${ }^{9}$. Valendo-se da ética popular, esses exergos articulam-se como discursos mantidos pela doxa, textos de verdades gerais, fundamentados no pressuposto. Como o lembra Lyotard: "O saber, nas histórias populares, credita-se a si próprio, pela pragmática da transmissão sem recorrer à argumentação e à administração das provas" ${ }^{10}$. Assinalamos, apesar de tudo, que a competência do destinador terá sido adquirida pelo fato de que ele foi, inicialmente, destinatário.

Os enunciados inaugurais do romance de Mary Shelley, Frankenstein, ilustram uma tal competência derivada da oralidade. Tendo recebido de Victor Frankenstein o relato, o destinatário Walton o entregará, por sua vez, a um outro destinatário, Mrs. Saville. Última autora de romance aterrorizante, Shelley fez da escrita uma estratégia moral: "Imagino que podereis extrair de minha história uma moral apropriada" ${ }^{11}$, diz Victor Frankenstein a Walton. O valor pragmático do saber-narrativo da obra, nesse texto, refere-se, pois, incessantemente, ao executor: o que se deve fazer.

\section{Racionalismo e ocultismo}

Entretanto, o fantástico não convoca esse único tipo de saber. O gênero nasce num período de regressão do sobrenatural "oficial" afiançado pelo aparelho jurídico (os últimos processos de bruxaria aconteceram na Europa por volta de 1712). Corresponde a um enfraquecimento do espírito re-

\footnotetext{
${ }^{7}$ Le Moine é escrito em 1793, enquanto Lewis ocupa o posto de Secretário na Embaixada inglesa de La Haye (ano da instauração do Terror na França...).

${ }^{8}$ Th. Owen, "La boule noire". In: La truie, Marabout fantastique, 1970.

${ }^{9}$ Th. Owen, "La métamorphose”. In: Pitié pour les ombres, Marabout fantastique, 1973

${ }^{10} \mathrm{~F}$. Lyotard, op. cit., p. 37.

${ }^{11}$ Mary Shelley, Frankenstein ou le Prométhée moderne. Garnier-Flammarion, 1979.
} 
ligioso, devido precisamente aos progressos do conhecimento. Irène Bessière observa que:

sob a pressão do racionalismo, os teólogos começam a diferenciar, de uma vez por todas, os milagres verdadeiros dos falsos milagres (...). O crédito atribuído aos relatos de prodígios, maléficos ou benéficos, é, no fundo, perigoso para a fé. Entretanto, o diabo existe, manifesta-se, as Escrituras e os Antigos atestam milagres e prodígios. Eis, então, o primeiro nível da contradição: oposição entre uma intenção racionalista e a carta do dogma (...). À figuração religiosa desses fenômenos corresponde sua representação literária que faz do imaginário o lugar de uma investigação (...)"12.

A estratégia discursiva de Ann Radcliffe caracteriza a atitude racionalista, uma vez que fatos e fenômenos recebem uma explicação lógica. Os temores e infortúnios das pobres heroínas de Os Mistérios do Castelo de Udolfo (1797) ou do Confessionário dos Penitentes Negros (1797) não dependem do sobrenatural, mas de impostores antropomórficos e bem reais. Ao contrário, Horace Walpole, em O Castelo de Otranto (1764), afirma a existência de fenômenos irracionais (o fantasma de Don Alonzo). Todavia, é Jacques Cazotte, em $O$ Diabo Enamorado, que inscreve verdadeiramente o fantástico como figura do questionamento. Conhece-se o argumento desse curto romance: um jovem espanhol, Álvaro, invoca Belzebu, que lhe aparece sob diversas formas (um cachorrinho, um pajem, etc.). O sujeito enamora-se de Biondetta, que se revela um espírito inferior à procura do amor salvador. Reencontrando sua mãe, Álvaro abandona definitivamente Biondetta/ Belzebu. Nesse discurso, reconhecem-se a crença de Álvaro no Diabo e a atitude racional da mãe, que fornece uma explicação pelo sonho às aventuras do filho. Por outro lado, $O$ Diabo Enamorado testemunha a permanência do pensamento mágico e dos saberes ocultos em um século "esclarecido". É que o século XVIII de Newton, de Buffon e da Enciclopédia, se foi a época do cientificismo de Messmer, de Lavateur, do mesmo modo conheceu os ocultistas. Cagliostro, o alquimista taumaturgo, pretendia possuir o saber do Egito faraônico. A própria "alta ciência" democratiza-se, já que a invocação dos espíritos e a alquimia geram, então, práticas sociais correntes. O Diabo Enamorado não ilustraria o que Foucault diz do século XVIII, a propósito do "conflito entre o tema de uma criação ordenada, adquirida de uma vez por todas, e o tema de uma natureza abundante, dotada de poderes enigmáticos" ${ }^{13}$ ?

${ }^{12}$ I. Bessière, Le Récit fantastique. Larousse Université, 1974, p. 70.

${ }^{13}$ M. Foucault, op. cit., p. 198. 
WILLEMIN, Patricia

\section{"Frankenstein" ou a crise do saber científico}

No início do século XIX, é Mary Shelley, com Frankenstein: o Moderno Prometeu, que assinala a crise do saber científico. Essa romântica faz de seu ator principal um herói infeliz do conhecimento, rompendo por esse meio com o arsenal tradicional do gótico. Os enunciados preliminares (cartas de Walton para sua irmã) abrem-se sobre o "código científico" do qual falava Barthes, a respeito de Edgar Poe. Walton, autodidata formado em ciências exatas, está em busca da passagem mítica em direção à vida, através dos espaços da morte (o Ártico). A essa pesquisa pseudocientífica, corresponde a de Victor Frankenstein. O subtítulo indica o código cognitivo inteiro, fazendo referência à obra de Percy Shelley, O Prometeu Libertado. Prometeu simboliza a ambição humana à procura do conhecimento, a libertação da autoridade. Ele é também transgressor da ordem, objeto aspirando a tornar-se sujeito. Sobre essa imagem mítica, projeta-se a de Adão que, contestando sua dependência, reivindicará o saber absoluto reservado a Deus. Nessa linhagem, Victor Frankenstein só pode ser uma vítima, punida por ter ultrapassado os limites do conhecimento. Notemos, entretanto, que ele não é castigado por Deus, ausente da obra, mas pelo objeto que ele produziu: sua experimentação. Para bem demonstrar que a ciência não cumpre mais sua função, esse romance convoca uma citação de Newton:

Eu dou a impressão de um menino brincando à beira-mar, que encontra aqui e ali um cascalho mais liso ou uma concha mais bonita que de costume, ainda que o grande oceano da verdade, inteiramente inexplorado, estenda-se diante de meus olhos ${ }^{14}$.

O pouco de legitimidade da figura paterna no texto é manifestamente responsável pelo engajamento de Victor Frankenstein nas ciências ocultas. Sua formação passa pela história natural. Determinantes, seus primeiros mestres: Cornellius Agrippa, o médico espagírico, Paracelsus, o alquimista. Mais tarde, tendo rejeitado esses "cientistas" que misturavam magia, teologia e matemáticas, Frankenstein freqüenta a universidade alemã de Ingolstad. Ali está às voltas com o ensino das ciências da natureza. Ao símbolo do racionalismo e do ideal teórico que é o professor Krempe, opõe-se o professor Waldmann, encarnação do pensamento pragmático. Verdadei-

${ }^{14}$ M. Shelley, op. cit., p. 97. 
ro Mefistófeles, este último seduzirá o protagonista. O químico moderno não é um verdadeiro mágico, "capaz de comandar os raios celestes, de imitar os tremores de terra (...)? Ele adquiriu poderes novos e ilimitados" ${ }^{15}$. Com a caução de um tal mestre, Victor parte em busca do saber absoluto: o princípio da vida, a abolição da morte.

Mas, paradoxalmente, abandona então o estatuto de sujeito para tornar-se objeto, o escravo do cognitivo. O texto desenvolve uma experimentação dos conhecimentos da fisiologia, da anatomia e, sobretudo, do galvanismo, como o chama Mary Shelley em sua Introdução de 1831:

Muitas e longas eram as conversas entre Lorde Byron e Shelley às quais eu assistia como ouvinte devota, mas silenciosa. (...) Elas falavam das experiências do Dr. Darwin (Não me refiro ao que o doutor realmente fez ou disse que fez, mas no meu próprio interesse, no que se falava que ele teria feito), que havia guardado um pedacinho de aletria numa caixa de vidro até que, por algum meio extraordinário, ele começou a se mover voluntariamente. Afinal de contas, não era assim que a vida devia ser criada. Talvez se pudesse reanimar um cadáver; as correntes galvânicas tinham dado sinal disso; talvez se pudesse fabricar as partes componentes de uma criatura, juntá-las e animá-las com o calor da vida. ${ }^{16}$.

Mesmo se o romance não oferece qualquer cientificismo manifesto, a autora, temendo as críticas, faz desaparecer um parágrafo inteiro que trata da eletricidade. Não é menos verdadeiro que, na diegese, o processo da descoberta respeita certas leis científicas, como a reflexão, a observação dos mecanismos de causalidade e a experimentação. É nesse "decoro científico" que Frankenstein vai se entregar a uma prática oculta. O lugar da "criação" situa-se em outra parte: "cela solitária separada de todos os outros apartamentos”. A lua preside inevitavelmente os trabalhos de extração de partes dos corpos humanos e de animais, depois à inoculação da "centelha de vida”, à animação do Golem. É sob o pretexto de cientificismo que Frankenstein realiza "a grande obra" dos alquimistas ${ }^{17}$. Racionalismo e magia reencontram-se no âmago da criação, como para demonstrar a negatividade e o perigo de toda busca de conhecimento absoluto.

Em um outro plano, é através dos capítulos consagrados ao "demônio" que Mary Shelley expõe a idéia rousseauniana da corrupção do homem

\footnotetext{
${ }^{15}$ Ibid., p. 107.

${ }^{16}$ Ibid., p. 343.

${ }^{17}$ Ibid., p. 117.
} 
pela sociedade; é aí que seu romance se encontra perpassado de "territórios arqueológicos”, o domínio do já dito. Por isso, no longo discurso romântico do despertar e da formação do monstro, inscreve-se em filigrana a teoria sensualista de Condillac: rejeição às idéias inatas, primado da sensação sobre o conhecimento. A criança selvagem, "o demônio", vai descobrir a sociedade através da literatura, percorrendo livros encontrados incidentalmente: A Ruína dos Impérios, de Valney, O Paraíso Perdido, de Milton, As vidas, de Plutarco e Os Sofrimentos do Jovem Werter, de Goethe (!). Então "o monstro”, aquele que nunca receberá nominação, chega a essa descoberta que, antes dele, seu mestre tinha feito:

O conhecimento aumenta os sofrimentos ${ }^{18}$.

Mas o que determina o envolvimento do monstro em direção ao "o mal e a morte” é verdadeiramente a sociedade. Ainda aí um outro território arqueológico, o do barão de Holbach: a consciência como efeito da experiência, produto da educação. Mais tarde, Maldoror fará a mesma descoberta: os homens conduzem ao mal. Portanto, se o cognitivo é o motor central do romance, ele só é representado para ser mais bem deslegitimado. Através de seu $O$ Médico e o Monstro, Stevenson terá a mesma compreensão do saber científico. Como Frankenstein, o Dr. Jekyll desenvolve pesquisas à margem da ciência oficial. Além disso, a homologia entre o sujeito Victor e sua criatura ("meu próprio fantasma libertado e forçado a destruir tudo o que lhe era caro" ${ }^{19}$ ) é atualizada em Stevenson por um só e mesmo ser que se desdobra sob o efeito de uma droga.

\section{Poe e o positivismo}

Após 1830, outros escritores do fantástico irão elaborar narrativas ligadas às teorias científicas então em curso. Edgar Allan Poe observará cientificamente fenômenos sobrenaturais, como o magnetismo. Se a elaboração das leis do magnetismo está na mesma categoria das da eletricidade, chegando ao eletromagnetismo, a ciência não experimentará esse conhecimento para outros fins senão... científicos. O próprio Poe, em O Caso do Sr. Valdemar, especula sobre os possíveis efeitos da magnetização in articulo mortis. Como o assinala Barthes,

\footnotetext{
${ }^{18}$ Ibid., p. 198
}

${ }^{19}$ Ibid., p. 143 
a mistura do estranho e do científico viu seu apogeu nesta metade do século XIX, à qual, grosso modo, pertence Poe: (...) o sobrenatural toma o álibi racionalista, científico; tal é o grito do coração dessa idade positivista: se pudéssemos acreditar cientificamente na imortalidade! $!^{20}$

Convocando a positividade da observação do fenômeno por vários focalizadores e especulando sobre o cientificismo dos vocábulos, Poe induz à "verdade" do fato. Da mesma maneira, "a revelação magnética" apresenta-se como uma especulação derivada de uma observação, o narrador abstendo-se de todo comentário final. Esse encanto do discurso "objetivo" aparece em outras novelas, de forma mais difusa. Assim, A Queda da Casa de Usher recebe uma explicação racional:

Talvez o olhar de um observador meticuloso pudesse ter descoberto uma fenda mal perceptível que, estendendo-se desde o telhado da fachada, descia em ziguezague até perder-se nas águas sombrias do lago ${ }^{21}$.

A mesma preocupação de descrição "positivista" anima uma outra novela, Ligéia:

O efeito fantasmagórico era vastamente realçado pela introdução artificial de uma forte corrente contínua de vento, por trás das cortinas, dando horrenda e inquietante animação ao todo ${ }^{22}$.

\section{"Drácula" e a busca de provas}

Se Poe conclui mais freqüentemente pela negação do sobrenatural, não vale da mesma forma para o irlandês Bram Stoker. Em seu Drácula (1897), os diferentes protagonistas (Jonathan Harker, Lucie, Mina) têm a prova da existência do famoso conde Drácula, figura típica da transgressão. O Vampiro simboliza a desordem que se introduz na sociedade vitoriana: sempre só, vive à noite e dorme de dia. Associal, existe desde o século XIV, mas de maneira atemporal. Mais grave ainda, Drácula quer invadir a Inglaterra

${ }^{20} \mathrm{R}$. Barthes, "Analyse textuelle d'um conte d'Edgar Poe". In: Sémiotique narrative et textuelle, Larousse Université, 1973, p. 35.

${ }^{21}$ E. A. Poe, "La chute de la Maison Usher". In: Histories extraordinaires, Garnier-Flammarion, 1965 , p. 137.

${ }^{22}$ E. A. Poe, "Ligeia", op. cit., p. 289. 
para aí estabelecer uma sociedade de vampiros, ocasionando uma desordem biológica nos "vampirizados" (só se alimentam de sangue, abandonam qualquer outra forma de consumo) e, sobretudo, uma desordem nos costumes (a pura Lucy torna-se o símbolo maldito da sensualidade). Esse princípio desestabilizador será perseguido pelos dois representantes da ordem, que são o Dr. Seward e o professor Van Helsing. Seward, o alienista, recusa toda crença, como bom homem de ciência. Protótipo do incrédulo na narrativa fantástica, ele deverá curvar-se como testemunha do irracional. Renunciará às certezas do positivismo, tal como Van Helsing, que questiona uma ciência incapaz de explicar a doença de Lucy:

Ah! Este é o grande defeito da ciência, que quer uma explicação para tudo e, quando não a encontra, afirma não haver nenhuma. Apesar disto, vemos todos os dias tais crenças se desenvolverem, sempre acreditando ser realmente novas. (...) Permita-me lhe informar que, em nossos dias, a ciência da eletricidade realiza práticas e experiências as quais seriam consideradas um sacrilégio pelos próprios descobridores, que acabariam queimados como bruxos se nascessem antes de seu tempo certo. (...) Sempre existiram mistérios na vida. ${ }^{23}$

Para encurralar o Mal, Van Helsing vai fazer um apelo à memória das tradições em matéria de vampirismo, e, portanto, à fé. Não exorcizou/ trepanou Renfield o louco/possuído de Drácula? A busca da ordem permanece presente ao longo de todo esse romance balizado por um número considerável de mémos (escritos tipografados, estenografados, datilografados). A produção desses enunciados, as crenças e a fé vencerão a resistência do Outro. A existência do sobrenatural não pode ser atestada. A conclusão de Harker testemunha isso:

Ficamos surpresos com o fato de que em todo aquele copioso material, o qual compunha nosso arquivo, não existia um único documento autêntico! Não passava de uma enorme quantidade de laudas datilografadas, com exceção dos últimos cadernos de notas de Mina, do dr. Seward e meus, além da exposição e do memorando de Van Helsing, todos escritos à mão. Certamente, não poderíamos pedir a ninguém, mesmo se o desejássemos, que os aceitasse como provas de uma história tão inacreditável. ${ }^{24}$.

O texto afirma a impossibilidade da vérédiction, esse "quadro no interior

${ }^{23}$ B. Stoker, Dracula, Marabout fantastique, 1963, pp. 278-279.

${ }^{24}$ Ibid., p. 507. 
do qual se exerce a atividade cognitiva de natureza epistêmica” (Greimas). A única prova trazida pelo romance é a da falta de procedimentos de verificação. Não se pode provar o que se prova, na ficção. Pode-se fazê-lo na ciência, parece dizer-nos Stoker? O que é feito desse saber científico que recua diante do que o ultrapassa? Eis como o fantástico de Stoker inscreve no vazio, nesse século XIX em declínio, a crise do cognitivo.

\section{Lovecraft e o herói científico}

Se existe um lugar onde fantástico e cognitivo trabalham ainda a ficção, no início do século seguinte, é realmente na obra de H.P. Lovecraft. Esse mestre norte-americano do terror rejeita, por sua parte, o sobrenatural e o ocultismo: "estupidez crassa, julgamento falso e rigidez de espírito". Suas produções representam, quase exclusivamente, sujeitos do conhecimento: o estudante de matemáticas de $A$ casa das bruxas, os professores lingüistas de L'Appel du Cthulhu, os cientistas de Nas Montanhas da Loucura. Todos esses protagonistas são movidos pela curiosidade intelectual. Buscam o conhecimento, mas esses racionalistas tornam-se vítimas de seu saber. O que o cognitivo lhes revela é que o homem é somente um objeto nas mãos das Potências ("Os Grandes Antigos"). Lembremos o postulado básico do discurso lovecraftiano:

Este mundo foi outrora habitado por raças diferentes da nossa que, em conseqüência da prática da magia negra, perderam seu poder e foram expulsas da terra. Mas elas continuam a viver no espaço, vagam nos arredores de nosso mundo, sempre prestes a retomar a posse de nossa terra.

Essas entidades ameaçam o homem de despossessão dele próprio. Sonhos e produções artísticas são induzidos por Cthulhu. É ele que se exprime através do homem. Lovecraft faz do sujeito um ser despossuído, perdido, isolado no espaço-tempo. Os baixos-relevos de Nas Montanhas da Loucura vão revelar a dois cientistas a arqueologia do universo, a história dessas entidades: os Grandes Antigos e seus escravos revoltados, os Shoggoths, os Mi-go vindos de Plutão e as hordas do Cthulhu. O olhar dirigido sobre esses signos encerra o saber no passado. Entretanto, os informantes descritivos das fabulosos sítios da Antártica e de R'Lyeh atualizam geometrias não-euclidianas, espaços com mais de três dimensões... É que a ciência atual só redescobre um saber antigo. Graças a essa concepção do universo, Lovecraft vai racionalizar os saberes mágicos, dado que os cultos satânicos 
das tribos esquimós e das povoações primitivas são somente uma versão deformada do culto prestado aos Grandes Antigos. Por um pacto firmado com Azathot, as bruxas obtiveram saberes científicos tal como Keziah, em A casa das bruxas que tinha adquirido conhecimentos matemáticos situados "além das mais modernas pesquisas de um Planck, um Heisenberg, um Einstein ou de um Sitter" ${ }^{25}$. Além disso, determinados livros, relatando o saber dos Grandes Antigos (como o célebre Necronomicon, do árabe demente Abdul Alhazreh), vão permitir ao estudante Gilman estabelecer relações entre as matemáticas transcendentais e os saberes arcaicos. A chave do conhecimento está nesse livro, nessa escritura maldita da qual um dístico afirma que "não está morto quem pode eternamente jazer; no decorrer das eras, a própria morte pode morrer". Quase todos os heróis de Lovecraft obtêm pela ciência a revelação de sua impotência, sem meio algum de superá-la. No abismo do tempo, o futuro é a despossessão. A ciência somente faz redescobrir.

\section{O saber impossível}

Se em sua relação com o mundo o fantástico aparece como uma reflexão sobre os saberes, é também questionamento do poder cognitivo do homem. São numerosos os textos que não fazem referência explícita a qualquer cientificismo; no entanto, o saber problematizado permanece a invariante de todas essas produções. Tomemos o exemplo mais recente de la Chambre ardente, de John Dickson Carr. O velho Miles é assassinado por uma mulher jovem vestida de marquesa de Brinvilliers. Uma narração do tipo realista, verossimilhante, leva a culpar uma enfermeira. Entretanto, o epílogo questiona essa afirmação. Que podemos saber exatamente? No discurso incerto de sua subjetividade, uma vizinha, Mary Stevens, declara ser uma "não-morta", ao mesmo tempo marquesa de Brinvilliers e Mary d'Aubray. Ela encarnaria uma força autônoma dedicada ao desaparecimento do Homem. Após Miles, quem será a próxima vítima? O leitor encontra-se às voltas com um caso, um enigma: Mary é louca? É um fantasma? Carr evita revelar a identidade de Mary. Pela coexistência de duas narrações paralelas, contraditórias (um significante para dois significados), esse romance inscreve a impossibilidade do saber. A outra volta do parafuso, de Henry James (1895), já não especulava sobre a oscilação entre a loucura da preceptora e a existência real dos fantasmas de Quint e da Srta. Jessel? A

${ }^{25}$ H. P. Lovecraft, “La Maison de la sorcière”. In: Dans l'abîme du temps. Denoël, 1954. 
ambigüidade discursiva permanece uma lei do fantástico, todo mundo está de acordo sobre esse ponto. O que não se tinha, talvez, acentuado suficientemente é sua relação estreita, genética, com os discursos do saber que ele questiona incansavelmente, mas dos quais nutre suas ficções. Figura do sentido fugidio, o fantástico não resolve, (para o maior prazer da leitura): excomunga o leitor do sentido, do saber, sinalizando assim a desordem do poder cognitivo desde o fim do século XVIII.

Tradução de: Maria Regina Borges-Osório e Maria Lucia Meregalli 